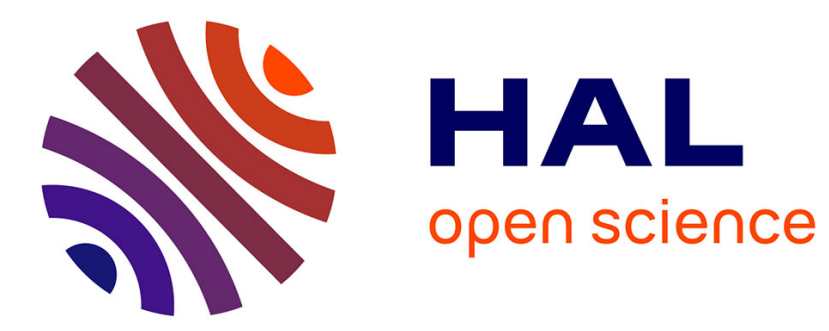

\title{
ULTRASONIC INVESTIGATION OF MODIFIED CRITICAL BEHAVIOUR IN THE STRONG RANDOM-FIELD SYSTEM Dy ( As0.17V0.83) O4
}

J. Page, J. Graham

\section{- To cite this version:}

J. Page, J. Graham. ULTRASONIC INVESTIGATION OF MODIFIED CRITICAL BEHAVIOUR IN THE STRONG RANDOM-FIELD SYSTEM Dy ( As0.17V0.83) O4. Journal de Physique Colloques, 1988, 49 (C8), pp.C8-1227-C8-1228. 10.1051/jphyscol:19888556 • jpa-00228768

\section{HAL Id: jpa-00228768 https://hal.science/jpa-00228768}

Submitted on 1 Jan 1988

HAL is a multi-disciplinary open access archive for the deposit and dissemination of scientific research documents, whether they are published or not. The documents may come from teaching and research institutions in France or abroad, or from public or private research centers.
L'archive ouverte pluridisciplinaire HAL, est destinée au dépôt et à la diffusion de documents scientifiques de niveau recherche, publiés ou non, émanant des établissements d'enseignement et de recherche français ou étrangers, des laboratoires publics ou privés. 


\title{
ULTRASONIC INVESTIGATION OF MODIFIED CRITICAL BEHAVIOUR IN THE STRONG RANDOM-FIELD SYSTEM Dy $\left(\mathrm{As}_{0.17} \mathrm{~V}_{0.83}\right) \mathrm{O}_{4}$
}

\author{
J. H. Page and J. T. Graham ${ }^{1}$ \\ Physics Dept., University of Manitoba, Winnipeg, Canada R3T $2 N 2$
}

Abstract. - Ultrasonic measurements of the soft-mode elastic constant $1 / 2\left(C_{11}-C_{12}\right)$ have been performed to investigate the pseudospin susceptibility of the random-field system $\mathrm{Dy}\left(\mathrm{As} \mathrm{V}_{1-x}\right) \mathrm{O}_{4}$. The susceptibility critical exponent $\gamma=1.73 \pm 0.07$ for $x=0.17$ is much larger than for the pure compound $(x=0)$, in reasonable agreement with predictions of the random-field Ising model.

While much of the recent interest in the effects of random fields on Ising phase transitions has focussed on magnetic systems, some of the most important features of this problem - the new critical behaviour and the slow equilibration near and below the transition temperature - can also be studied experimentally in mixed Jahn-Teller (JT) compounds [1]. The structural phase transitions in these materials [2] are driven by a linear coupling between a lattice distortion and electronic energy levels of rare-earth or transition ions, giving rise in most cases to a ferrodistortive effective ion-ion interaction that is very well described by a pseudospin Ising Hamiltonian $-\Sigma J_{i j} \sigma_{i}^{z} \sigma_{i}^{z}$. In mixed crystals, the ionic size mismatch generates static random strain fields, one component of which has the right symmetry to couple to the electronic operators $\sigma_{i}^{z}$ and give the additional random-field (RF) term $-\Sigma h_{i} \dot{\sigma}_{i}^{z}$ in the pseudospin Hamiltonian. Thus mixed JT compounds are the structural counterparts of a ferromagnet in a random magnetic field, and are potentially important since this magnetic system cannot be realized in practice, all magnetic experiments having been performed on diluted antiferromagnets in a uniform field.

Of the mixed JT systems studied so far, $\operatorname{Dy}\left(A s_{x} V_{1-x}\right) O_{4}$ is probably the most interesting in the context of RF effects: the JT interactions in the parent compounds $\mathrm{DyVO}_{4}$ and $\mathrm{DyAsO}_{4}$ are of comparable magnitude [3], the interactions are not diluted on mixing so that only the RFs should depend on concentration $x$, and the interactions have a large short-range component leading to non-classical critical behaviour in the range of temperatures that are normally accessible experimentally $[3,4]$. Indeed our previous electric susceptibility and ultrasonic measurements [1] in these compounds have shown evidence of metastable ordering, history dependence and modified critical behaviour that includes some previously unexplored features of random-field Ising systems. In this paper we present the results of new ultrasonic velocity measurements that were performed to obtain better data on the critical behaviour of both mixed $(x=0.17)$ and pure $(x=0)$ samples of Dy $\left(\mathrm{As}_{x} \mathrm{~V}_{1-x}\right) \mathrm{O}_{4}$.

In these Dy compounds, the lattice distortion is from tetragonal to orthorhombic symmetry corresponding to the soft acoustic shear mode with elastic constant $1 / 2\left(C_{11}-C_{12}\right)$. Hence just above the distortion temperature $T_{\mathrm{D}}$, the softening of $1 / 2\left(C_{11}-C_{12}\right)$ is inversely proportional to the divergence of the pseudospin susceptibility, i.e. $1 / 2\left(C_{11}-C_{12}\right) \propto \chi^{-1} \propto t^{\gamma}$ where $t=\left(T-T_{\mathrm{D}}\right) / T_{\mathrm{D}}$ is the reduced temperature and $\gamma$ is the susceptibility critical exponent. As in our earlier work [5], we have determined $\gamma$ from the ultrasonic velocity of [100] longitudinal waves by subtracting the temperature-independent contribution of $1 / 2\left(C_{11}+C_{12}\right)$ from the measured elastic constant $\rho v^{2}=C_{11}=1 / 2\left(C_{11}+C_{12}\right)+1 / 2\left(C_{11}-C_{12}\right)$. (This trick avoids the prohibitively large ultrasonic attenuation encountered near $T_{\mathrm{D}}$ when $1 / 2\left(C_{11}-C_{12}\right)$ is measured directly using [110] shear waves.) Figure 1 shows the temperature dependence of $C_{11}$ for the mixed and pure samples from 4 to $80 \mathrm{~K}$. As the temperature is lowered, $C_{11}$ decreases continuously until a mini-

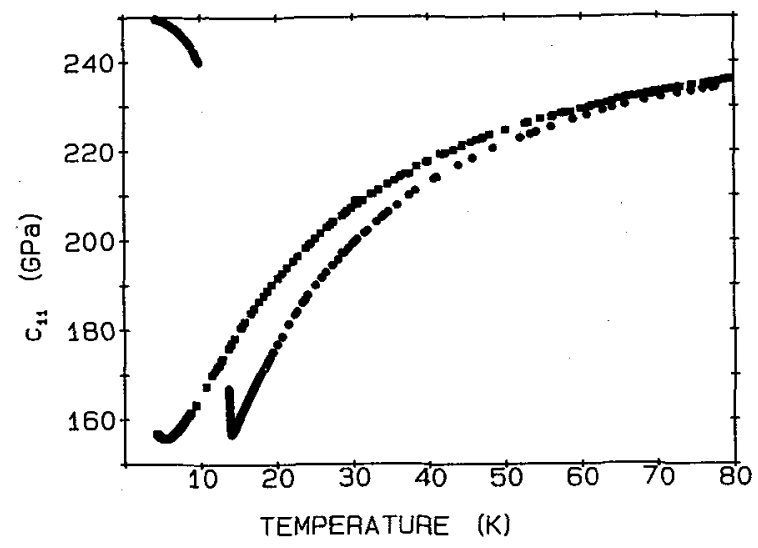

Fig. 1. - Elastic constant $C_{11}$ vs. temperature for $\operatorname{Dy}\left(\mathrm{As}_{x} \mathrm{~V}_{1-x}\right) \mathrm{O}_{4}$ with $x=0.17(-)$ and $x=0(\bullet)$.

\footnotetext{
${ }^{1}$ Permanent address: Physics Department, Queen's Univerity, Kingston, Canada K7L 3N6.
} 
mum is reached at the phase transition temperature for each sample, implying a second-order phase transition in both cases. From the values of $T_{\mathrm{D}}(5.57 \mathrm{~K}$ and $14.06 \mathrm{~K}$ for the mixed and pure samples respectively) it follows that the transition temperature in the mixed crystal is $40 \%$ that of pure $\mathrm{DyVO}_{4}$, indicating that the random fields are strong. The figure also shows that the random fields cause the minimum of $C_{11}$ to be less sharp but more symmetric in the mixed material. Within experimental error, both the degree of softening of $C_{11}$ and the values of $C_{11}$ at $T_{\mathrm{D}}$ are the same for both samples, consistent with the result that $1 / 2\left(C_{11}-C_{12}\right)=0$ at the phase transition for $\mathrm{Dy}\left(\mathrm{As}_{0.17} \mathrm{~V}_{0.83}\right) \mathrm{O}_{4}$ as well as for pure $\mathrm{DyVO}_{4}$. Thus we have taken $1 / 2\left(C_{11}+C_{12}\right)=$ $C_{11}\left(T_{\mathrm{D}}\right)$ in determining the temperature dependence of $1 / 2\left(C_{11}-C_{12}\right)$ from our data. This is further justified by the good agreement between these values of $C_{11}\left(T_{\mathrm{D}}\right)$ and $1 / 2\left(C_{11}+C_{12}\right)$ measured in another rare earth zircon $\mathrm{TmVO}_{4}[6]$.

Figure 2 shows a $\log -\log$ plot of $1 / 2\left(C_{11}-C_{12}\right)$ versus reduced temperature $t$ for the two samples. In pure $\mathrm{DyVO}_{4}$, reasonable power-law behaviour is found for $10^{-2}<t<10^{-1}$ with slope $\gamma=1.13 \pm 0.07$. This value confirms that mean field behaviour $(\gamma=1.0)$ is not observed in this range of reduced temperatures, but it is somewhat smaller than the Ising exponent $\gamma=1.25$ expected from earlier birefringence data [4]. The deviations from this power law seen at lower $t$, where possible errors in $T_{\mathrm{D}}$ and in the zero of the elastic constant have greatest effect, may simply re-

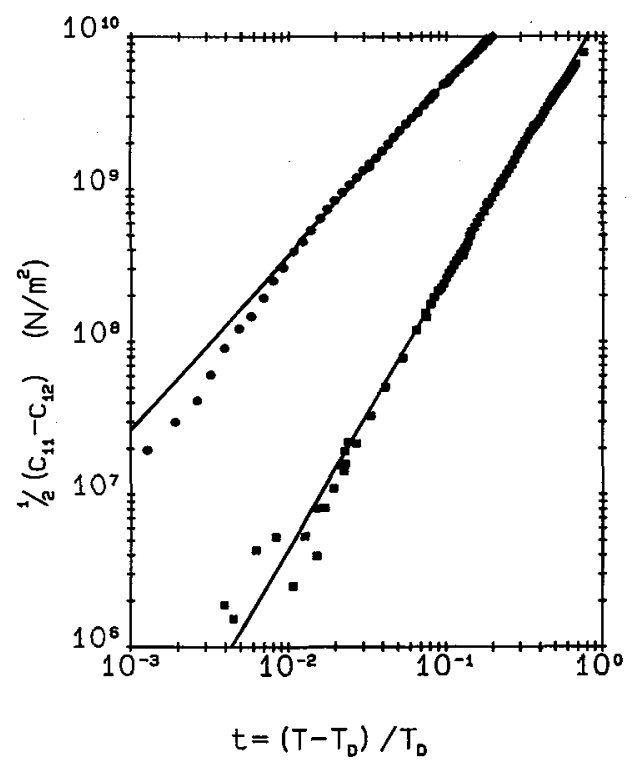

Fig. 2. - Elastic constant $1 / 2\left(C_{11}-C_{12}\right)$ vs. reduced temperature for $\mathrm{Dy}\left(A \mathrm{~s}_{x} \mathrm{~V}_{1-x}\right) \mathrm{O}_{4}$ with $x=0.17(\mathrm{~m})$ and $x=0(\bullet)$. The straight lines have slopes 1.73 and 1.13 as discussed in the text. sult from weak random fields due to a small amount of flux impurities; we note that $T_{D}$ in this sample is about $4 \%$ lower than in our best samples studied by electric susceptibility measurements [3]. Nonetheless it is clear from figure 2 that $\gamma$ appears to be much larger in the mixed crystal $\mathrm{Dy}\left(\mathrm{As}_{0.17} \mathrm{~V}_{0.83}\right) \mathrm{O}_{4}$, with $\gamma=1.73 \pm 0.07$ fitting the data over nearly two orders of magnitude in reduced temperature. This RF exponent $\gamma=1.73$ is consistent with the value $1.75 \mathrm{ex}-$ pected if RF critical behaviour is correctly described by a dimensionality reduction of 1 [7], with the value $1.75 \pm 0.02$ observed in experiments on dilute antiferromagnets [8], and with the value $2.0 \pm 0.5$ found in the most recent simulations [9]. However, the exponent $\gamma=1.73$ apparently disagrees with recent scaling predictions for the RF Ising model in $2+\varepsilon$ dimensions [10] which give $\gamma=(3-d+1.5 \varepsilon) / \varepsilon=1.5$ for $d=3$, $\varepsilon=1$. A detailed comparison with this and other work may nevertheless be complicated by possible correlations between the random fields at different sites and the effects of transverse random fields of either $A_{1 g}$ or $B_{2 g}$ symmetry. Future experimental work will further investigate possible effects of concentration gradients in the mixed sample $\left(\Delta x / x<10^{-3}\right.$ over $2.5 \mathrm{~mm}$ in typical samples [1]) and combine shear wave measurements of $1 / 2\left(C_{11}-C_{12}\right)$ with the longitudinal ultrasonic data to obtain a more definitive check on the correct zero of the elastic constant.

[1] Graham, J. T., Maliepaard, M., Page, J. H., Smith, S. R. P. and Taylor, D. R., Phys. Rev. $B 35$ (1987) 2098.

[2] Gehring, G. A. and Gehring, K. A., Rep. Prog. Phys. 38 (1975) 1.

[3] Page, J. H., Taylor, D. R. and Smith, S. R. P., J. Phys, C 17 (1984) 51.

[4] Gehring, G. A., Harley, R. T. and Macfarlane, R. M., J. Phys. C 13 (1980) 3161.

[5] Page, J. H., Maliepaard, M. C. and Taylor, D. R., Phonon Scattering in Condensed Matter V, Springer Series in Solid State Sciences, Eds. A. C. Anderson and J. P. Wolfe (Springer-Verlag, Berlin) Vol. 68 (1986) 275.

[6] Melcher, R. L., Phys. Acoust., Eds. W. P. Mason and R. N. Thurston (Academic, New York) 12 (1976) 1.

[7] Aharony, A., Imry, Y. and Ma, S., Phys. Rev. Lett. 37 (1976) 1364.

[8] Belanger, D. P., King, A. R. and Jaccarino, V., Phys. Rev. B 31 (1985) 4538.

[9] Ogielski, A. T. and Huse, D. A., Phys. Rev. Lett. 56 (1986) 1298.

[10] Bray, A. J. and Moore, M. A., J. Phys. C 18 (1985) L927. 